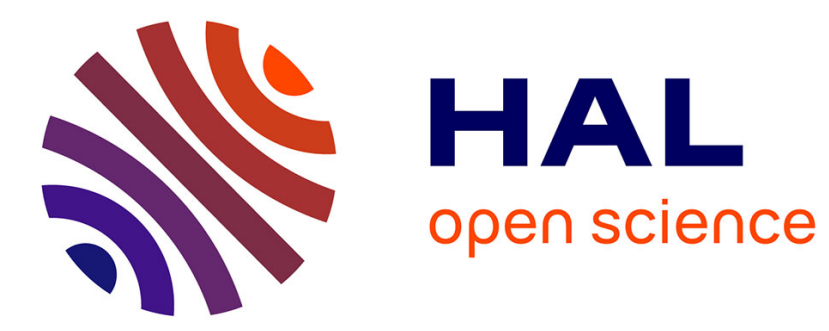

\title{
Facteurs de variation du taux protéique du lait de vache: Etude dans des exploitations du Puy-de-Dôme
}

\author{
G. Agabriel, J.B. Coulon, G. Marty, N. Cheneau
}

\section{To cite this version:}

G. Agabriel, J.B. Coulon, G. Marty, N. Cheneau. Facteurs de variation du taux protéique du lait de vache: Etude dans des exploitations du Puy-de-Dôme. Productions Animales, 1990, 3 (2), pp.137-150. hal-00895896

\section{HAL Id: hal-00895896 https://hal.science/hal-00895896}

Submitted on 1 Jan 1990

HAL is a multi-disciplinary open access archive for the deposit and dissemination of scientific research documents, whether they are published or not. The documents may come from teaching and research institutions in France or abroad, or from public or private research centers.
L'archive ouverte pluridisciplinaire HAL, est destinée au dépôt et à la diffusion de documents scientifiques de niveau recherche, publiés ou non, émanant des établissements d'enseignement et de recherche français ou étrangers, des laboratoires publics ou privés. 
INRA Prod. Anim., 1990, 3 (2), 137 - 150

\section{G. AGABRIEL, J.B. COULON* G. MARTY, N. CHENEAU ${ }^{* *}$}

ENITA, Marmilhat, 63370 Lempdes

* INRA Laboratoire de la Lactation

Theix 63122 Saint-Genès-Champanelle

* * Contrôle Laitier

19, avenue Marx-Dormoy

63038 Clermont-Ferrand

\section{Facteurs} de variation du taux protéique du lait de vache

\author{
Etude dans des exploitations \\ du Puy-de-Dôme
}

Depuis une dizaine d'années, et plus particulièrement dans les zones herbagères du Centre et du Sud-Ouest de la France, on observe une diminution sensible du taux protéique du lait de vache. Cette évolution pose des problèmes importants dans des régions où la majeure partie du lait est transformée en fromages. La teneur du lait en protéines est en effet un des principaux facteurs de variation du rendement fromager et de la qualité des fromages.

Les facteurs de variations de la composition chimique du lait et plus particulièrement du taux protéique ont fait l'objet de nombreux travaux expérimentaux et sont bien connus (Bonaiti 1985, Hoden et al 1985, Rémond 1985, Le Dore et al 1986, Sutton 1989). Parallèlement, des études ont été entreprises dans les exploitations (EDE Haute-Saône 1985, Coulon et Binet 1987, Coulon et al 1988, Coulon et Lilas 1988, Froc et al 1988). Elles ont confirmé l'importance prédominante du stade physiologique, de la saison de vêlage, de la race des animaux et de l'alimentation sur les variations des taux

\section{Résumé}

42 exploitations laitières du Puy-de-Dôme, adhérentes au Contrôle Laitier, ont fait l'objet d'une enquête détaillée concernant à la fois la structure de l'exploitation et du troupeau, la qualité des fourrages et les pratiques alimentaires hivernales et estivales. Ces données ont permis d'analyser les variations du taux protéique du lait d'une exploitation à l'autre. Bien que ces exploitations aient été homogènes par la race des animaux (Pie-noire) et le type de ration de base utilisée (ensilage d'herbe) des écarts importants ont été observés d'un troupeau à l'autre $(3,2 \mathrm{~g} / \mathrm{kg}$ entre les taux protéiques moyens annuels des étables extrêmes). Les taux protéiques élevés (hivernaux, estivaux ou annuels) ont été associés à la conjonction d'une maîtrise de l'alimentation (qualité de la ration de base, conduite du pâturage), d'un niveau génétique élevé (index TMMU) et d'un groupement des vêlages en début d'hiver. L'analyse des données individuelles mensuelles de la production et de la composition du lait de $\mathbf{1 6 0 0}$ vaches de ces exploitations a permis de mettre en évidence les effets propres respectifs du stade de lactation et de la saison sur ces variables. A stade de lactation constant, les taux protéiques les plus faibles sont observés du mois de février au mois de juillet, mais les productions laitières sont les plus élevées à cette période. Les écarts entre mois extrêmes sont d'autre part plus importants pour les animaux en fin de lactation que pour ceux en début de lactation. Le mois d'août apparaît comme très défavorable pour la production laitière des animaux en début de lactation. butyreux et protéique. Ces études ont d'autre part mis en évidence les interactions entre ces différents facteurs et la variabilité de leur hiérarchie selon les situations régionales. Dans ces études, le système alimentaire, et en particulier le type de ration de base, est toujours apparu essentiel. Cependant, rares sont les travaux où l'on disposait de manière systématique d'informations sur le niveau génétique (index) des animaux. De plus, la comparaison des variations de la production laitière et de la composition chimique du lait d'un troupeau à l'autre est souvent difficile à réaliser. Dans les conditions françaises, les vêlages ne sont en effet pas répartis de façon uniforme au cours de l'année et leur distribution varie selon Ies élevages. Il est donc difficile d'isoler l'effet de la saison de celui du stade de lactation à partir de données moyennes à l'échelle du troupeau. L'effet global de la saison, direct (longueur du jour) ou indirect (par l'intermédiaire de l'alimentation) est pourtant important aussi bien sur la production que sur la composition chimique du lait (Jarrige et Journet 1959, Lampo et al 1966, Spike et Freeman 1967).

Le premier objectif de cette étude a donc été de préciser l'ampleur des variations du taux protéique d'un troupeau à l'autre et ses principales causes, y compris génétiques, dans un échantillon d'exploitations utilisant une même race (Pie-noire) et distribuant des rations hivernales à base d'ensilage d'herbe. Le second objectif a été, à partir des données individuelles issues de ces troupeaux, de dégager l'influence propre de la saison de celui du stade de lactation, et d'analyser les éventuelles interactions entre ces 2 facteurs. 


\section{1 / Conduite de l'étude}

\section{1 / Origine des données}

Cette étude a été réalisée à partir des données du Contrôle Laitier et d'enquêtes effectuées dans des exploitations du Puy-de-Dôme, concernant la campagne 87-88. Les objectifs de cette étude ont conduit à définir a priori un certain nombre de caractéristiques des exploitations analysées. L'échantillon retenu n'est donc pas représentatif des exploitations du département ni même de celles adhérentes du Contrôle Laitier (tableau 1).

Parmi les 804 exploitations laitières adhérentes du Contrôle Laitier du Puy-de-Dôme, 2 échantillons initiaux ont été constitués selon les types de ration offerte aux vaches laitières: «classique » (ration $\mathrm{C}$ : ensilage d'herbe + foin), ou «améliorée » (ration A : ensilage d'herbe + regain + pulpes). Les contraintes communes à toutes les exploitations ont concerné le type génétique (Pie-noir), les effectifs (entre 15 et 50 vaches), la part de primipares dans l'effectif total (entre 15 et $35 \%$ ), et la proportion d'animaux indexés (au moins
$70 \%$ avec un coefficient de détermination supérieur à 0,45 ).

Compte-tenu de ces contraintes, 93 (ration C) et 45 (ration A) exploitations ont été retenues, parmi lesquelles on a tiré au hasard 21 dans chaque groupe. Trois exploitations du groupe C s'étant par la suite avérées plus proches du groupe $\mathrm{A}$, les effectifs finaux de ces 2 groupes ont donc été de 18 (ration C) et 24 (ration A). Les principales caractéristiques de ces exploitations sont précisées au tableau 1. Dix-neuf d'entre elles sont situées dans les Dômes, 12 dans les Combrailles, 5 en Limagne et 6 réparties dans les autres petites régions naturelles du département

Sur chacune de ces exploitations, des données relatives 1) à la structure de l'exploitation, 2) à l'utilisation des surfaces (fourrages récoltés, conduite du pâturage...) 3) au rationnement des animaux et 4) aux caractéristiques zootechniques et génétiques (index lait et TMMU) du troupeau ont été recueillies (annexe 1). Parallèlement, les valeurs mensuelles de la production laitière, du nombre de cellules du lait et de sa composition chimique ont été relevées à l'échelle du troupeau d'une part, et pour chaque vache d'autre part, entre novembre 1987 et octobre 1988.

Tableau 1. Principales caractéristiques moyennes des exploitations.

\begin{tabular}{|c|c|c|c|c|}
\hline Type de ration & $\begin{array}{c}\text { Ration } \\
\text { classique }\end{array}$ & $\begin{array}{c}\text { Ration } \\
\text { améliorée }\end{array}$ & $\begin{array}{l}\text { Moyenne } \\
\text { générale }\end{array}$ & $\begin{array}{c}\text { Contrôle } \\
\text { laitier }\end{array}$ \\
\hline Nombre d'exploitations & 18 & 24 & 42 & 804 \\
\hline Altitude moyenne (m) & 772 & 783 & $778 \pm 199$ & \\
\hline Pluviométrie moyenne (mm/an) & 1058 & 1158 & $1112 \pm 215$ & \\
\hline SAU moyenne (ha) & 52 & 57 & $55 \pm 30$ & 47 \\
\hline $\begin{array}{l}\text { Bâtiments (nb d'exploitations) } \\
\text { - stabulation entravée } \\
\text { - stabulation libre ou logettes }\end{array}$ & $\begin{array}{l}9 \\
9\end{array}$ & $\begin{array}{l}12 \\
12\end{array}$ & $\begin{array}{l}21 \\
21\end{array}$ & \\
\hline $\begin{array}{l}\text { Période de vêlage } \\
\text { - automne (1) } \\
\text { - hiver-été }\end{array}$ & $\begin{array}{r}6 \\
12\end{array}$ & $\begin{array}{l}13 \\
11\end{array}$ & $\begin{array}{l}19 \\
23\end{array}$ & \\
\hline Effectif vaches laitières & 34 & 39 & $37 \pm 11$ & 31 \\
\hline Production annuelle (kg) & 181850 & 245900 & $218450 \pm 81440$ & 157130 \\
\hline Production/vache/an (kg) & 5457 & 6201 & $5883 \pm 965$ & 5090 \\
\hline Durée de lactation (j) & 304 & 304 & $304 \pm 16$ & 276 \\
\hline Taux butyreux annuel (g/kg) & 36,3 & 37,0 & $36,7 \pm 1,9$ & 36,5 \\
\hline Taux protéique annuel (g/kg) & 29,1 & 29,6 & $29,4 \pm 0,9$ & 29,8 \\
\hline Cellules $(1000 / \mathrm{ml})$ & 278 & 289 & $282 \pm 50$ & \\
\hline $\begin{array}{l}\text { Concentré : } \\
\text { - kg/vache/an } \\
\text { - g/kg lait }\end{array}$ & $\begin{array}{l}895 \\
166\end{array}$ & $\begin{array}{c}1042 \\
167\end{array}$ & $\begin{array}{c}984 \pm 281 \\
167 \pm 33\end{array}$ & $\begin{array}{l}852 \\
167\end{array}$ \\
\hline Index lait (kg) (2) & -175 & -34 & $-94 \pm 220$ & -126 \\
\hline Index TMMU (g/kg) & $-0,2$ & 0,1 & $0,0 \pm 0,4$ & $-0,1$ \\
\hline
\end{tabular}

(1) Plus de $60 \%$ des vêlages entre septembre et décembre.

(2) Les moyennes des index génétiques sont celles calculées une fois par an par le Centre Régional Informatique sur une

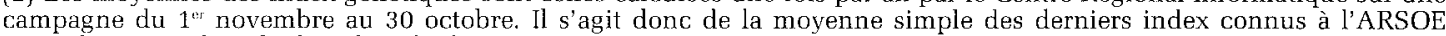
pour chaque vache à la date du calcul, ce qui regroupe des index en base 87 et des index en base 88 . Aucune correction n'a été apportée pour ces écarts de base, ce qui gonfle artificiellement les index lait exprimés en base 87. Cependant, on a vérifié que la proportion de ces index base 87 était la même d'un groupe d'exploitations à l'autre (75\%). Cette approximation n'a pas d'effet sur les index TMMU car la base de ces index n'a pas changé entre 87 et 88. 


\section{2 / Analyse des données}

\section{a / Analyse à l'échelle du troupeau}

L'analyse de ces données a été faite selon la démarche suivante: après avoir décrit l'évolution moyenne au cours de l'année des variables caractérisant la production et la composition du lait, une analyse factorielle des correspondances (AFC, logiciel Statitcf) a été réalisée sur les 42 exploitations. Les variables introduites dans cette analyse sont celles précisées en annexe 1. Trois d'entre elles ont été utilisées pour caractériser le taux protéique du lait: la moyenne annuelle, la moyenne des mois de mars et d'avril (TP hivernal), et le taux du mois d'août (TP estival). Ces 2 périodes sont en effet celles où l'effet propre de la saison sur le taux protéique est le plus défavorable (figure 5). Ces 3 variables ont été introduites comme variables supplémentaires dans l'AFC. Des situations favorables ou défavorables pour le taux protéique (définies par des associations de facteurs) ont ainsi pu être mises en évidence. Les exploitations les plus représentatives de ces situations ont alors été étudiées plus précisément. Elles ont été choisies à partir de leur position, la plus proche possible de celle des facteurs explicatifs, sur les plans factoriels de l'AFC.

\section{b / Analyse des données individuelles}

Les valeurs mensuelles individuelles $(n=$ 13 587) de production laitière, de taux butyreux et de taux protéique de 1600 vaches appartenant à 38 des 42 troupeaux ont été utilisées pour différencier les effets respectifs du stade de lactation et de la saison. Pour cela, pour chaque mois calendaire, les valeurs des différentes variables ont été regroupées par mois de lactation. Pour chaque variable, une matrice $12 \times 10$ des moyennes a ainsi été obtenue. L'évolution des moyennes de lignes représente l'effet propre de la saison, et celle des moyennes de colonnes l'effet propre du stade de lactation (10 mois de lactation, le $10^{\circ}$ mois regroupant les animaux entre le $275^{\mathrm{e}}$ et le $400^{\mathrm{e}}$ jour de lactation). Les effectifs d'animaux par case (mois calendaire * mois de lactation) ont varié de 17 (vaches en premier mois de lactation en juillet) à 357 (vaches en premier mois de lactation en novembre); les effectifs marginaux par ligne ont varié de 580 (aôit) à 1680 (novembre) et ceux par colonne de 1122 ( $9^{\circ}$ mois de lactation) à 1520 ( $3^{\mathrm{e}}$ mois de lactation). Cette analyse a été réalisée également en séparant les animaux, d'une part selon le numéro de lactation (primipares : 3205 données, multipares : 10382 données) et d'autre part selon le type de ration de base hivernale utilisée (classique : 4568 données, améliorée : 7857 données).

\section{2 / Résultats}

\section{1 / Evolution annuelle de la production et de la composition du lait des troupeaux}

En moyenne, les taux butyreux et protéique annuels ont été de 36,7 et $29,4 \mathrm{~g} / \mathrm{kg}$, pour une production laitière de $5883 \mathrm{~kg} / \mathrm{vache} / \mathrm{an}$ (moyenne économique) (tableau 1). Par ailleurs, les exploitations du groupe A ont produit un lait plus riche $(+0,7 \mathrm{~g} / \mathrm{kg}$ de taux butyreux et $+0,5 \mathrm{~g} / \mathrm{kg}$ de taux protéique) et plus abondant (+ $750 \mathrm{~kg} / \mathrm{an}$ ) que celles du groupe C. La production laitière a été en moyenne plus élevée en hiver qu'en été en raison du nombre important d'exploitations pratiquant des vêlages d'automne $(45 \%$ des exploitations présentent plus de $60 \%$ des vêlages entre les mois de septembre et décembre), mais aussi d'une moins bonne persistance de la production laitière en été (cf paragraphe 2.4.), comme c'est très généralement observé (Coulon et al 1988, Contrôle laitier, 1988). Inversement, les taux butyreux et protéique, qui ont présenté une évolution parallèle au cours de l'année, ont été minimums en fin d'hiver et maximums en fin d'été (écart moyen entre les mois extrêmes de respectivement 7,0 et $4,3 \mathrm{~g} / \mathrm{kg}$ ). Le taux protéique a fortement augmenté à la mise à l'herbe $(+1,7 \mathrm{~g} / \mathrm{kg}$ entre mars et mai), comme dans d'autres régions (Coulon et Binet 1987). Le taux de cellules du lait a été minimum en hiver (241000 cellules $/ \mathrm{ml}$ entre novembre et mars) et maximum en été ( 344000 cellules/ml entre juillet et septembre), ce qui a souvent été observé par ailleurs (Coulon et al 1988, Coulon et Lilas 1988).

Ces valeurs et ces évolutions moyennes présentent cependant des variations très importantes d'une exploitation à l'autre. Les écarts entre les exploitations extrêmes atteignent ainsi $4750 \mathrm{~kg}$ pour le lait, 6,5 g/kg pour le taux butyreux, 3,2 g/ $\mathrm{kg}$ pour le taux protéique et 450000 pour les cellules. Ces écarts sont encore plus importants lors des 2 périodes critiques pour le taux protéique: respectivement 5,5 et $6 \mathrm{~g} / \mathrm{kg}$ pour les taux protéiques hivernaux et estivaux. Quelques exemples d'évolutions extrêmes sont présentés à la figure 1.

Figure 1. Evolution du taux protéique au cours de l'année dans 3 exploitations extrêmes.

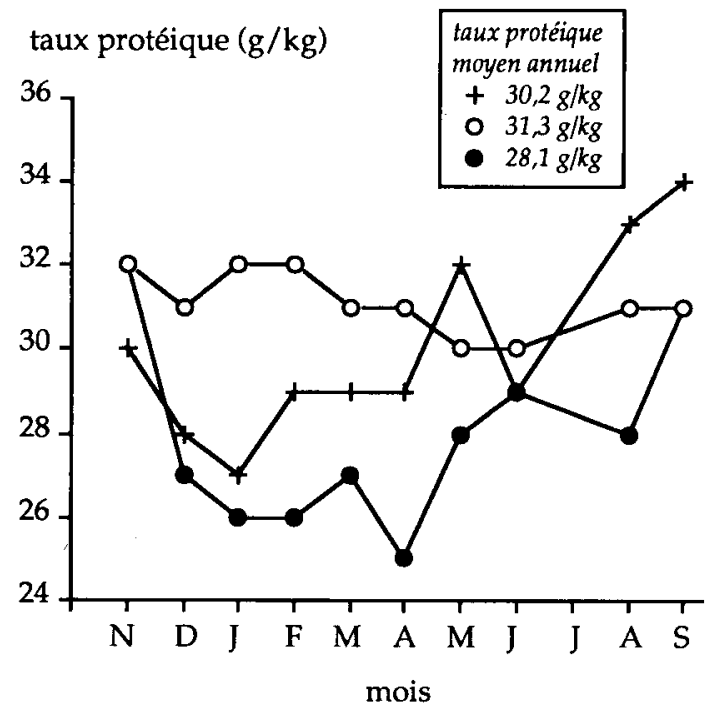

Les écarts de taux protéique entre les exploitations atteignent $6 \mathrm{~g} / \mathrm{kg}$ en fin d'hiver et en milieu d'été. 
Tableau 2. Principales caractéristiques des exploitations des 4 groupes constitués à partir de l'AFC.

\begin{tabular}{|c|c|c|c|c|}
\hline Groupe & 1 & 2 & 3 & 4 \\
\hline Effectif & 8 & 9 & 7 & 7 \\
\hline \multicolumn{5}{|l|}{ Caractéristiques de l'exploitation } \\
\hline - SAU (ha) & 59 & 50 & 52 & 37 \\
\hline - Qualité des sols & superficiels & profonds & profonds & superficiels \\
\hline - Période de vêlage & année & automne & année & automne/année \\
\hline - Ration de base hivernale & $7 \mathrm{C}+1 \mathrm{~A}$ & $3 \mathrm{C}+6 \mathrm{~A}$ & $3 \mathrm{C}+4 \mathrm{~A}$ & $2 \mathrm{C}+5 \mathrm{~A}$ \\
\hline \multicolumn{5}{|l|}{ Alimentation des vaches laitières } \\
\hline - Surface prairies temporaires (ha) & 17 & 0 & 2 & 8 \\
\hline - Nombre de parcelles pâturées & 5 & 5 & 3 & 8 \\
\hline $\begin{array}{l}\text { - Durée de séjour sur les parcelles } \\
\text { au printemps (j) }\end{array}$ & 6 & 7 & 10 & 4 \\
\hline - Déprimage & non & oui & oui/non & oui/non \\
\hline $\begin{array}{l}\text { - Fourrage complémentaire } \\
\text { au pâturage }\end{array}$ & non & transitions & non/transitions & automne/été \\
\hline $\begin{array}{l}\text { - Fumure azotée sur parcelles } \\
\text { ensilées ou pâturées (U/ha) }\end{array}$ & 100 & 125 & 122 & 61 \\
\hline - Conduite du pâturage & mauvaise & $\begin{array}{l}\text { moyenne/ } \\
\text { bonne }\end{array}$ & moyenne & $\begin{array}{l}\text { bonne/ } \\
\text { moyenne }\end{array}$ \\
\hline - Qualité des fourrages secs & moyenne & bonne & bonne & bonne \\
\hline - Qualité des ensilages & moyenne & moyenne & moyenne & bonne \\
\hline - Concentré (g/kg lait) & 167 & 151 & 176 & 162 \\
\hline \multicolumn{5}{|l|}{ Caractéristiques génétiques du troupeau } \\
\hline - Index lait $(\mathrm{kg})$ & -323 & 34 & -124 & -9 \\
\hline - Index TMMU (g/kg) & $-0,3$ & 0,2 & $-0,1$ & 0,3 \\
\hline \multicolumn{5}{|l|}{ Caractéristiques du lait } \\
\hline - Lait (kg) & 5032 & 6576 & 5689 & 6191 \\
\hline - Taux butyreux annuel (g/kg) & 36,6 & 37,3 & 35,4 & 38,0 \\
\hline - Taux protéique annuel $(\mathrm{g} / \mathrm{kg})$ & 29,1 & 29,4 & 29,0 & 30,2 \\
\hline - Taux protéique hiver $(\mathrm{g} / \mathrm{kg})$ & 28,1 & 28,4 & 28,1 & 29,4 \\
\hline - Taux protéique été $(\mathrm{g} / \mathrm{kg})$ & 29,1 & 31,0 & 29,9 & 31,1 \\
\hline - Cellules $(1000 / \mathrm{ml})$ & 308 & 278 & 257 & 262 \\
\hline
\end{tabular}

\section{2 / Analyse des différences de taux protéique entre les exploitations (figure 2 et tableau 2)}

L'AFC a permis de mettre en évidence 4 groupes de 7 à 9 exploitations différents par leur taux protéique estival (mois d'août) (groupes 1 et 2) ou hivernal (mois de mars et d'avril) et annuel (groupes 3 et 4 ).

Les exploitations du groupe 1 (TP estival faible : 29,1 g/ $/ \mathrm{kg}$ ) sont caractérisées par des vêlages répartis sur toute l'année, un niveau génétique faible (index lait et TMMU égaux respectivement à - $323 \mathrm{~kg}$ et $-0,3 \mathrm{~g} / \mathrm{kg}$ ), une maîtrise médiocre du pâturage et l'utilisation d'une ration hivernale de type classique $(7$ fois sur 8). Leur niveau de production individuel (5032 kg/vache/an) est d'autre part le plus faible des 4 groupes. Celles du groupe 2 (TP estival élevé : $31,0 \mathrm{~g} / \mathrm{kg}$ ) sont beaucoup plus productives (6576 kg/vache/an), présentent des vêlages groupés à l'automne, ont un niveau génétique élevé (index lait et TMMU égaux respectivement à $+34 \mathrm{~kg}$ et $+0,2 \mathrm{~g} / \mathrm{kg}$ ), et maîtrisent bien la conduite des surfaces fourragères et l'alimentation (déprimage, bonne conduite du pâturage, maîtrise des périodes de transition alimentaires, ration hivernale de type améliorée dans 6 cas sur 9). Le taux protéique moyen annuel est cependant peu différent entre les groupes 1 et $2(0,3 \mathrm{~g} / \mathrm{kg}$ d'écart à l'avantage du groupe 2). La différence apparaît à la mise à l'herbe et s'accroît jusqu'au mois d'août où elle est maximale $(1,9 \mathrm{~g} / \mathrm{kg})$. La meilleure maîtrise du pâturage dans le groupe 2 est confirmée par l'évolution de la production laitière en été: malgré un stade physiologique moyen plus favorable pour le groupe 1 , la diminution de la production laitière est identique dans les 2 groupes (respectivement - 4,4 et - 4,7 kg/j entre mai et août, dans les groupes 1 et 2).

Les exploitations du groupe 3 (TP hivernal faible: $28,1 \mathrm{~g} / \mathrm{kg}$ ) sont caractérisées par un index TMMU faible $(-0,1 \mathrm{~g} / \mathrm{kg})$, une certaine intensification de la production fourragère (fumure azotée élevée), mais aussi une conduite médiocre du pâturage, une qualité moyenne des ensilages utilisés, et une proportion importante de vêlages d'été $(31 \%$ des vêlages entre juillet et septembre). Les exploitations du groupe 4 (TP hivernal élevé : 29,4 $\mathrm{g} / \mathrm{kg}$ ) présentent à l'inverse un index TMMU 

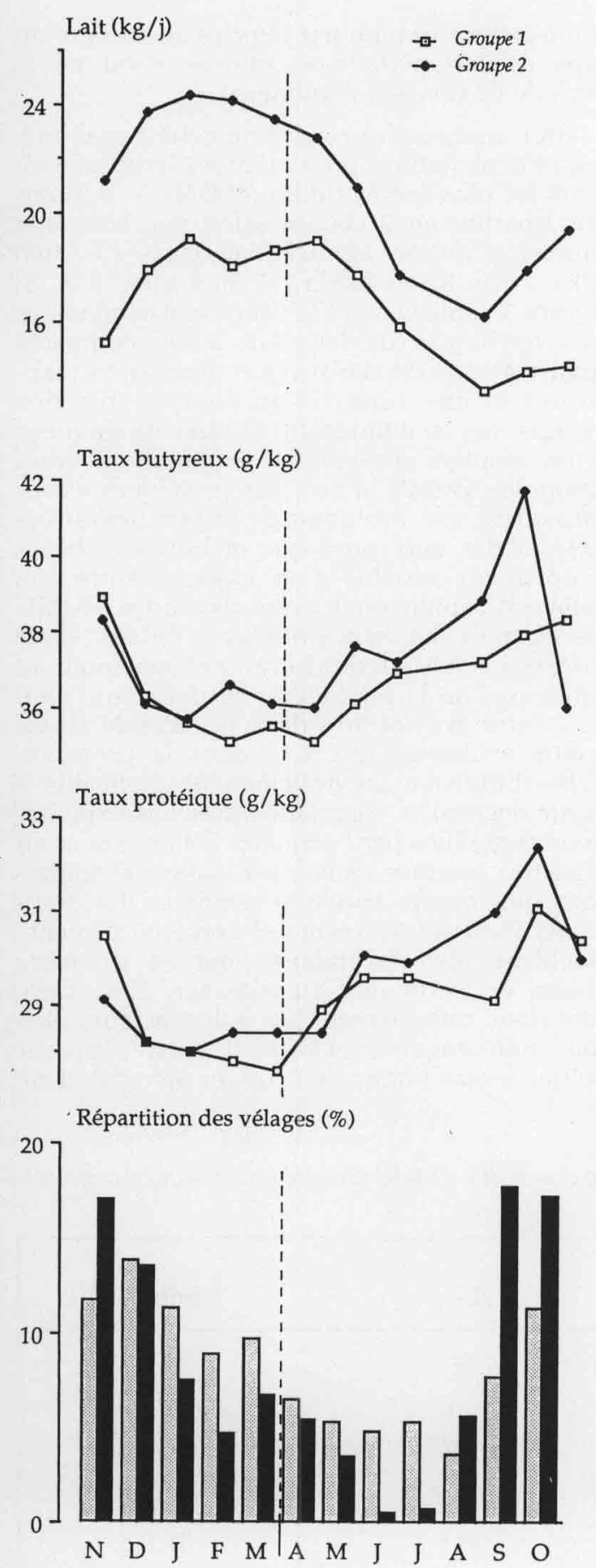

mise a l'herbe

élevé ( $+0,3 \mathrm{~g} / \mathrm{kg}$ ), des petites structures, une maîtrise à la fois du pâturage et de l'alimentation hivernale (qualité des fourrages utilisés, ration hivernale de type amélioré 5 fois sur 7) et une proportion importante de vêlages en début d'hiver ( $48 \%$ entre novembre et janvier). L'écart de taux protéique entre ces 2 groupes est en moyenne sur l'année de $1,2 \mathrm{~g} / \mathrm{kg}$. Il est légèrement supérieur en hiver $(1,7 \mathrm{~g} / \mathrm{kg}$ entre novembre et janvier contre 1,1 entre juin et août). Le niveau de production laitière et l'évolution de cette production sont voisins dans ces
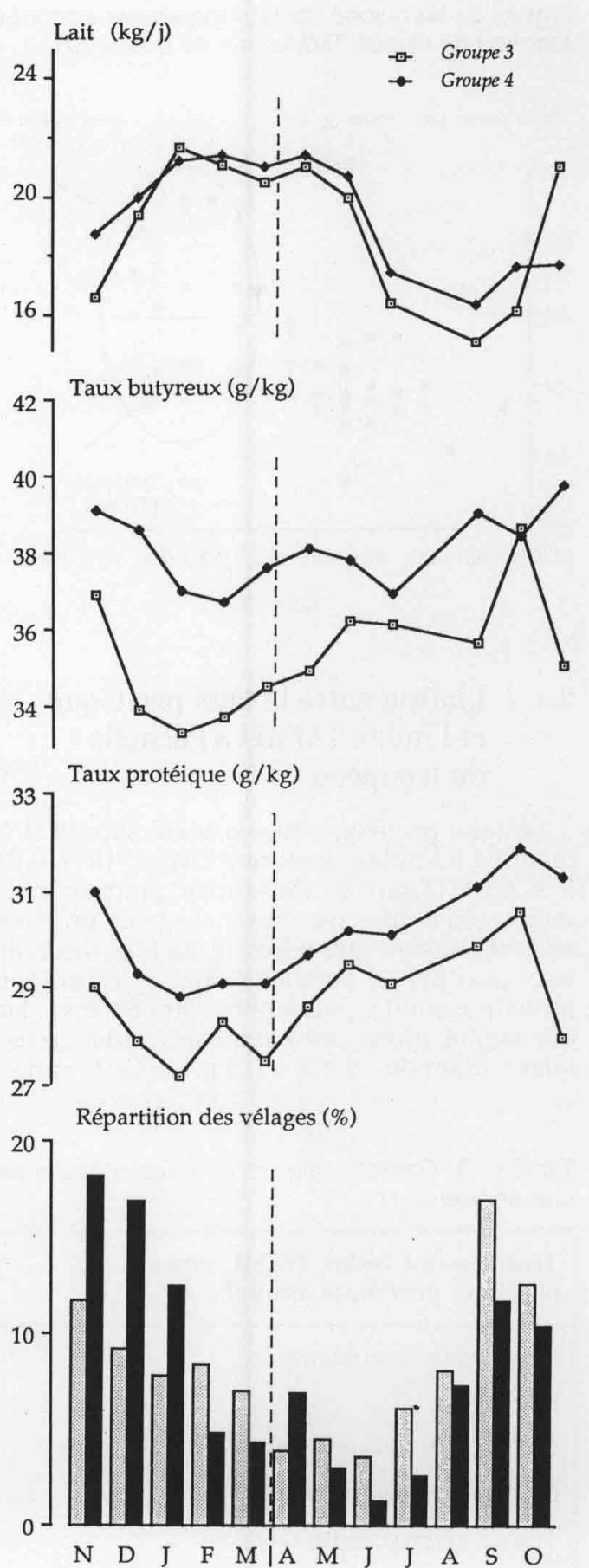

mise a I'herbe

Figure 2. Evolution des caractéristiques du lait au cours de l'année selon les groupes d'exploitations. 
Figure 3. Variations du taux protéique annuel en fonction de l'index TMMU ( $n=42$ troupeaux).

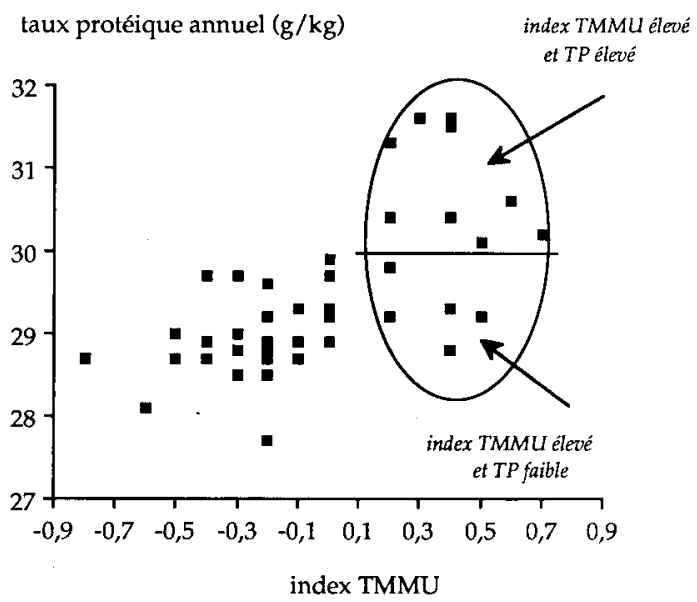

\section{3 / Liaison entre le taux protéique et l'index TMMU à l'échelle du troupeau}

Le taux protéique moyen a été significativement lié à l'index génétique TMMU $(\mathrm{R}=0,64$; $\mathrm{P}<0,01$ ) (figure 3). Cependant, pour un même index génétique, les écarts de taux protéique annuel peuvent atteindre $3 \mathrm{~g} / \mathrm{kg}$ (cas des index taux positifs), et parallèlement, un même taux protéique annuel (faible) peut être observé dans des exploitations présentant des index génétiques variant de $-0,4$ à $+0,3 \mathrm{~g} / \mathrm{kg}$. Cette variabi- lité n'est pas réduite par la prise en compte du type de ration de base utilisée et/ou de la période de vêlage des animaux.

Pour analyser les causes de cette variabilité, les 14 exploitations présentant les index génétiques les plus élevés (index TMMU $>0,2$ ) ont été réparties en 2 classes selon que leur taux protéique moven annuel était élevé $(>30,0$ $\mathrm{g} / \mathrm{kg}, \mathrm{n}=9)$ ou faible $(<30,0 \mathrm{~g} / \mathrm{kg}, \mathrm{n}=5)$ (figure 3, tableau 3), et l'évolution moyenne des caractéristiques de leur lait a été comparée (figure 4). Malgré des niveaux génétiques identiques et une répartition comparable des vêlages, ces évolutions ont été très différentes: d'une manière générale, les exploitations ayant des index TMMU et des taux protéiques élevés présentent une évolution de la production laitière et des taux protéique et butyreux beaucoup moins variable d'un mois à l'autre que celle des exploitations ayant des index TMMU élevés mais des taux protéiques faibles. Cette différence est particulièrement marquée au printemps où la production laitière chute de 6 $\mathrm{kg} / \mathrm{j}$ entre avril et juin dans la seconde classe contre seulement $2,8 \mathrm{~kg} / \mathrm{j}$ dans la première. Cette différence est difficilement explicable à partir des seules caractéristiques des exploitations recueillies par l'enquête. Celles-ci sont en effet très voisines dans les 2 classes et traduisent une bonne conduite générale des troupeaux (tableau 3), même si certains éléments semblent plus favorables pour la première classe, en particulier au pâturage. Ces écarts sont donc certainement liés à des facteurs plus fins, non enquêtés. On peut ainsi supposer qu'une moins bonne maîtrise du pâturage dans

Tableau 3. Caractéristiques des exploitations présentant des index TMMU élevés, selon leur taux protéique annuel.

\begin{tabular}{|lcc|}
\hline $\begin{array}{l}\text { Troupeaux à index TMMU élevé } \\
\text { et à taux protéique annuel : }\end{array}$ & élevé & faible \\
\hline Nombre de troupeaux & 9 & 5 \\
Effectif & 34 & 42 \\
Production annuelle $(\mathrm{kg})$ & 235000 & 255000 \\
Production/vache/an $(\mathrm{kg})$ & $\mathbf{6} 665$ & 6112 \\
Taux butyreux annuel $(\mathrm{g} / \mathrm{kg})$ & 38,5 & 37,0 \\
Taux protéique annuel $(\mathrm{g} / \mathrm{kg})$ & 30,9 & 29,3 \\
Période de vêlage & & 3 \\
$\quad$ - automne & 5 & 2 \\
$\quad$ - hiver-été & 4 & 156 \\
Concentré (g/kg lait) & 156 & 77 \\
Index lait (kg) & 58 & 0,3 \\
Index TMMU (g/kg) & 0,4 & \\
Ration de base hivernale & & 1 \\
$\quad$ - classique & 2 & 4 \\
$\quad$ - améliorée & 7 & $3 / 5$ \\
Déprimage & $\mathbf{6} / 9$ & bonne \\
Conduite du pâturage & bonne \\
Qualité des ensilages & bonne \\
\hline
\end{tabular}


Figure 5. Evolution des caractéristiques individuelles du lait selon le stade de lactation (a) ou la saison (à stade de lactation constant) (b).
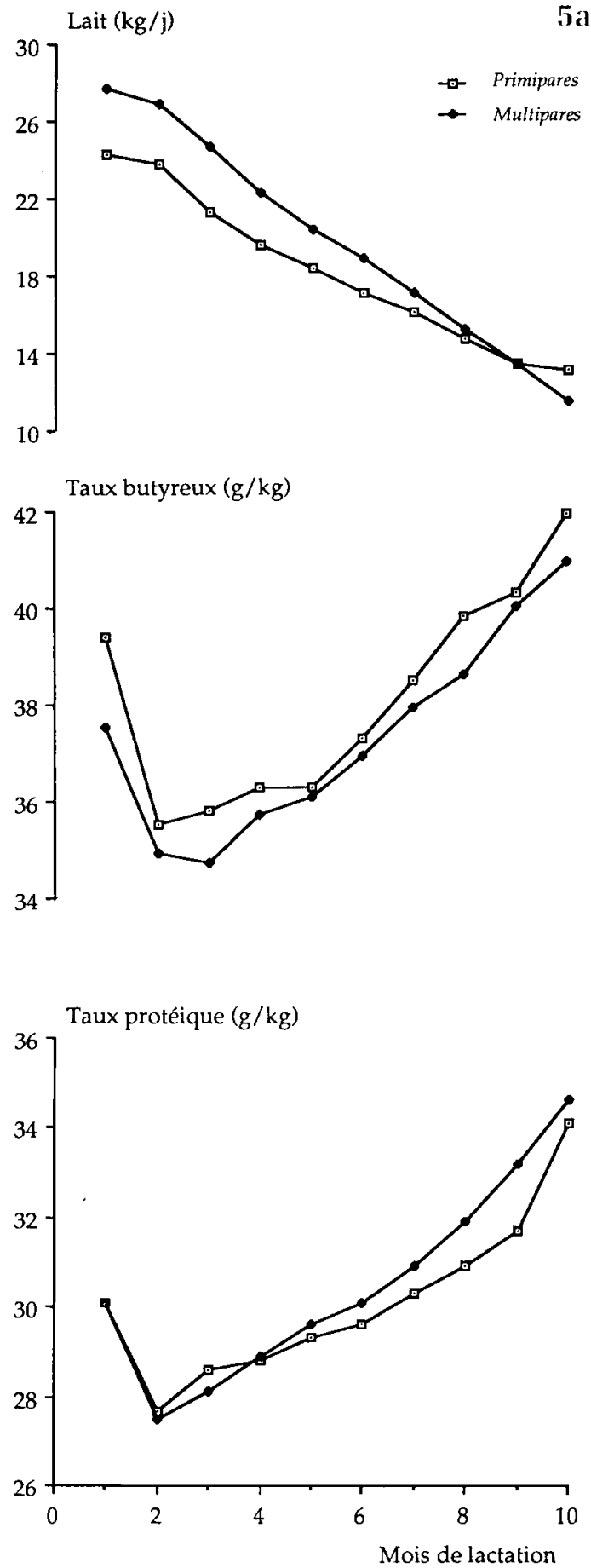

taux protéique plus importante après une ration " classique » $(+1,6 \mathrm{~kg} / \mathrm{j}$ et $+1,4 \mathrm{~g} / \mathrm{kg})$ qu'après une ration " améliorée » $(+0,3 \mathrm{~kg} / \mathrm{j}$ et $0,0 \mathrm{~g} / \mathrm{kg}$ ).

L'évolution de la production et de la composition du lait au cours de la saison a différé selon que les animaux étaient en début ( 3 premiers mois, 4454 données mensuelles), milieu ( $4^{\mathrm{e}}$ à $7^{\mathrm{e}}$ mois, 5408 données) ou fin de lactation ( $8^{\mathrm{e}}$ à $10^{\circ}$ mois, 3826 données) (figure 7). En particulier, le mois d'août apparaît comme très défavorable pour les vaches en début de lactation $(-5,9 \mathrm{~kg} / \mathrm{j}$ de lait et $-2,0 \mathrm{~g} / \mathrm{kg}$ de taux butyreux par rapport aux mois de mai à juillet). D'autre part, l'augmentation de production laitière et la diminution des taux au cours de l'hi-
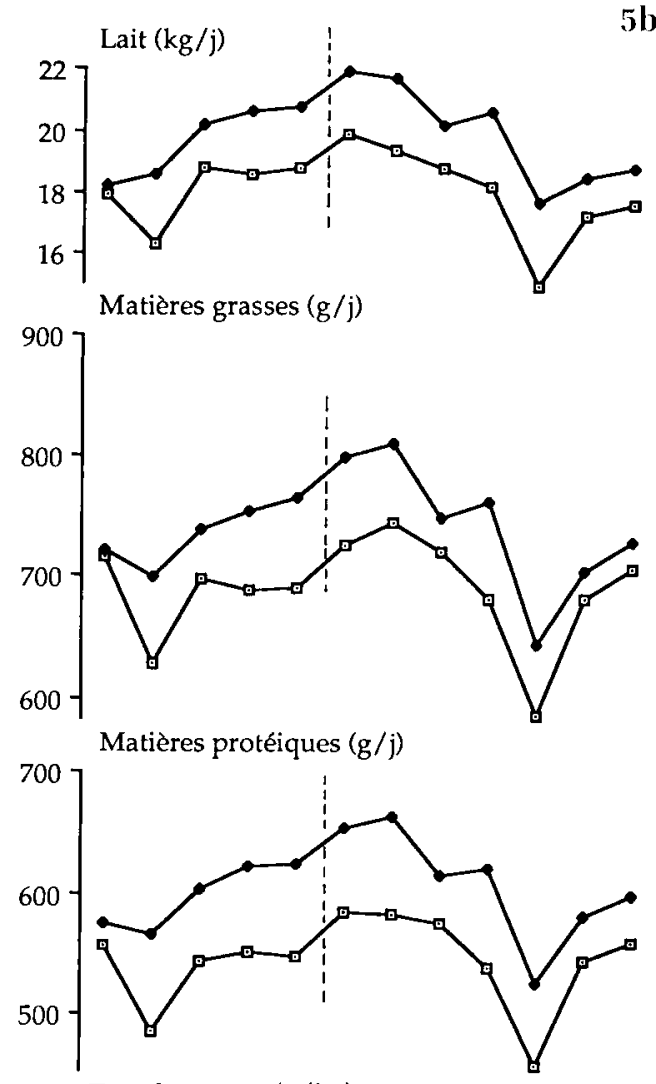

Taux butyreux $(\mathrm{g} / \mathrm{kg})$

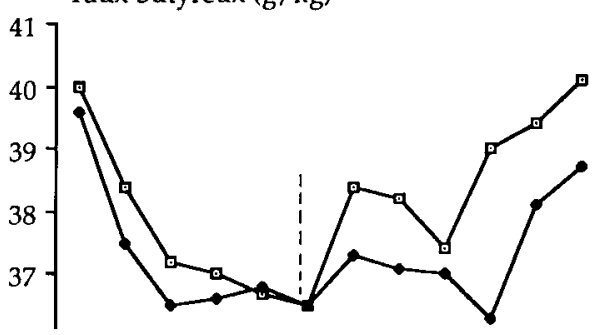

Taux protéique $(\mathrm{g} / \mathrm{kg})$

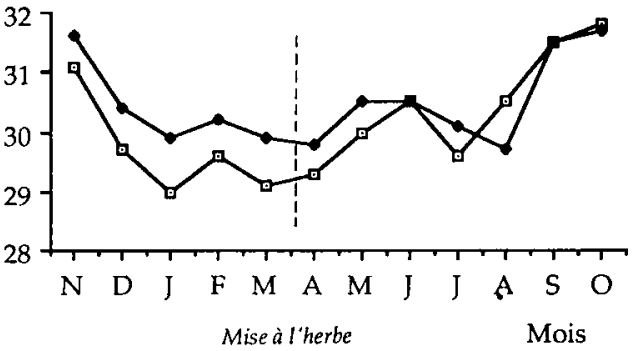

ver ont été d'autant plus importantes que les animaux étaient à un stade de lactation plus avancé (respectivement $+2,0,+3,5$ et $+4,7$ $\mathrm{kg} / \mathrm{j}$ de lait en début, milieu et fin de lactation; - 1,4, - 1,6 et - 2,4 g/kg de taux protéique, entre novembre et avril).

Ces effets combinés du stade de lactation et de la saison conduisent à des évolutions différentes de la production et de la composition du lait selon la période de vêlage (figure 8). Chez les vaches multipares, les vêlages de fin d'été (août à octobre) conduisent ainsi à une meilleure persistance de la production et à des taux plus stables et plus élevés $(+0,7 \mathrm{~g} / \mathrm{kg}$ de taux protéique, $\mathrm{P}<0,01$ ) que les vêlages de fin d'hivor (lwrier a avril) (tableau 4). Les lactations 


\begin{tabular}{|lccccc|ccc|}
\hline & \multicolumn{4}{c}{ Primipares } & \multicolumn{3}{c|}{ Multipares } \\
Période de vêlage & FMA & MJJ & ASO & NDJ & FMA & MJJ & ASO & NDJ \\
\hline Effectif & 49 & 18 & 129 & 151 & 256 & 127 & 314 & 405 \\
Index lait (kg) & 287 & 202 & 250 & 205 & -198 & -205 & -108 & -169 \\
Index TMMU (g/kg) & 0,3 & 0,7 & 0,3 & 0,3 & $-0,1$ & $-0,1$ & $-0,1$ & $-0,1$ \\
Lait (kg) (1) & 4312 & 4209 & 5125 & 4684 & 5809 & 5528 & 6210 & 6195 \\
TP (g/kg) (1) & 29,2 & 28,6 & 29,1 & 29,0 & 29,4 & 29,8 & 30,1 & 29,4 \\
\hline
\end{tabular}

Tableau 4. Effet de la période de vêlage sur la production laitière et le taux protéique (données individuelles). démarrant en début d'été (mai à juillet), bien qu'ayant le niveau initial le plus élevé, présentent une production totale inférieure de près de $700 \mathrm{~kg}(\mathrm{P}<0,01)$ à celle des lactations démarrant en fin d'été ou en début d'hiver. Cet écart est certainement sous-évalué pour les vêlages de fin d'été (et en particulier ceux d'août) : leur démarrage de lactation est en effet le plus faible de tous bien que leur valeur génétique soit la meilleure (tableau 4).

Les écarts de production laitière et de taux protéique mis en évidence à l'échelle du troupeau entre les différents groupes d'exploitations ne sont pas modifiés par l'analyse réalisée

Figure 6. Evolution des caractéristiques individuelles du lait au cours de la saison (à stade de lactation constant) en fonction du type de ration de base hivernale.

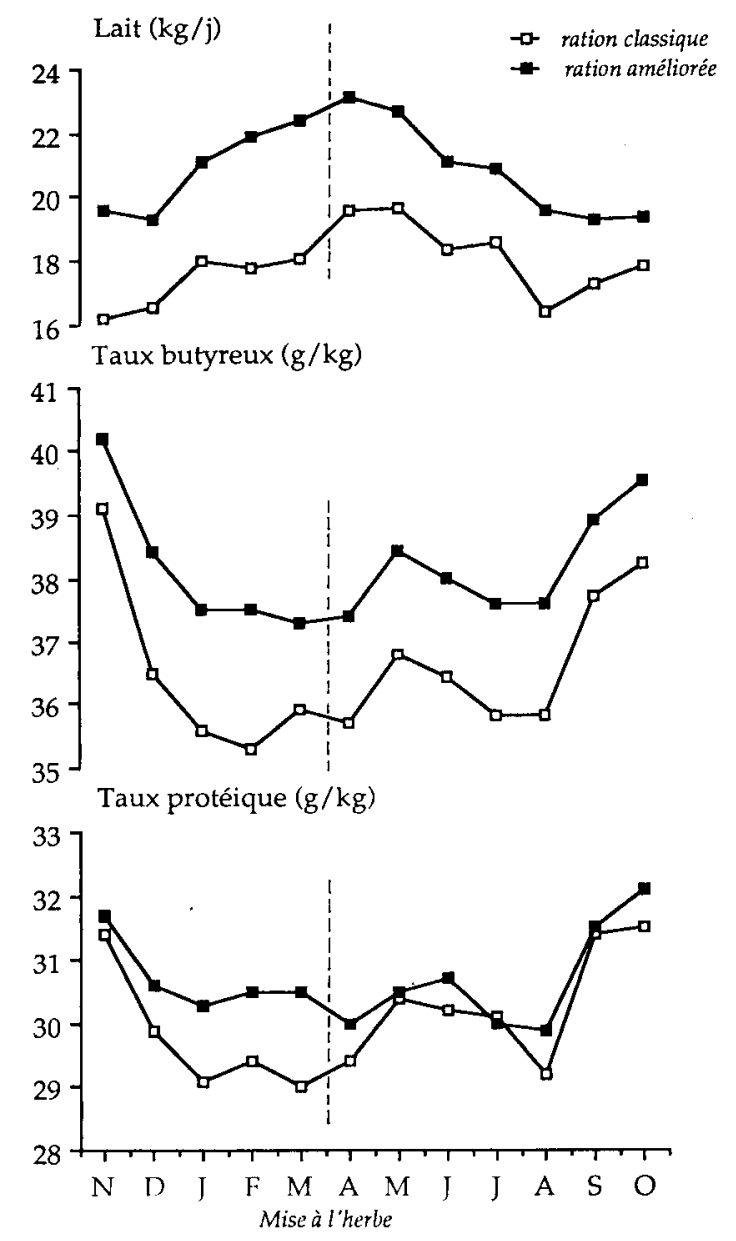

à l'échelle de l'animal, qui permet de prendre en compte des caractéristiques individuelles supplémentaires (période de vêlage, numéro de lactation, index génétique) (tableau 5). Pour un même niveau génétique, et compte-tenu de l'effet de la période de vêlage, les animaux recevant une ration « améliorée » produisent près de $600 \mathrm{~kg}$ de plus $(\mathrm{P}<0,01)$ d'un lait légèrement plus riche en protéines $(+0,3 \mathrm{~g} / \mathrm{kg})$ que ceux recevant une ration «classique». De même, les animaux des troupeaux présentant des caractéristiques de milieu favorables (définis par l'AFC) présentent une production laitière et un taux protéique supérieur de respectivement $550 \mathrm{~kg}$ et $1,0 \mathrm{~g} / \mathrm{kg}(\mathrm{P}<0,01)$ à ceux des troupeaux ayant des caractéristiques de milieu défavorables. Ces effets sont donc bien dûs à des facteurs du milieu autres que la période de vêlage des animaux, et qui s'y ajoutent.

\section{Discussion - Conclusion}

Cette étude a permis de mettre en évidence des écarts considérables de taux protéique d'une exploitation à l'autre, même lorsque 2 des principaux facteurs de variations de ce taux (la race et le type de fourrage utilisée dans la ration de base) sont contrôlés, et que l'on se situe dans une population sélectionnée en partie sur ses compétences techniques (adhérents du Contrôle Laitier).

Ses résultats confirment le rôle prépondérant du stade physiologique des animaux, de leur alimentation et de leur niveau génétique comme facteurs de variation du taux protéique du lait. L'étude de ce dernier facteur a cependant pu manquer de précision compte-tenu de l'utilisation de l'index TMMU; la publication des index taux séparés (1989 pour les mâles, 1990 ou ultérieurement pour les femelles) permettra des analyses plus précises. Ils mettent en évidence certaines interrelations entre ces facteurs, et montrent donc la nécessité de les prendre en compte simultanément. Ainsi, l'absence d'écart de taux protéique hivernal entre les groupes 1 et 2 peut s'expliquer par l'influence du stade physiologique moyen, moins avancé dans le groupe 1, qui contre-balance l'effet favorable des facteurs alimentaires. Cependant, il est vraisemblable que ces facteurs ne sont qu'incomplètement maîtrisés, comme le montre l'augmentation importante du taux protéique entre avril et mai, $1+0,7$ $\mathrm{g} / \mathrm{kg}$ ), caractéristique d'une sous-alimentation 
Figure 7. Evolution des caractéristiques du lait selon la saison, en fonction du stade de lactation des animaux.

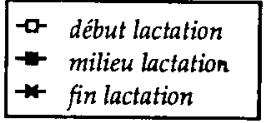

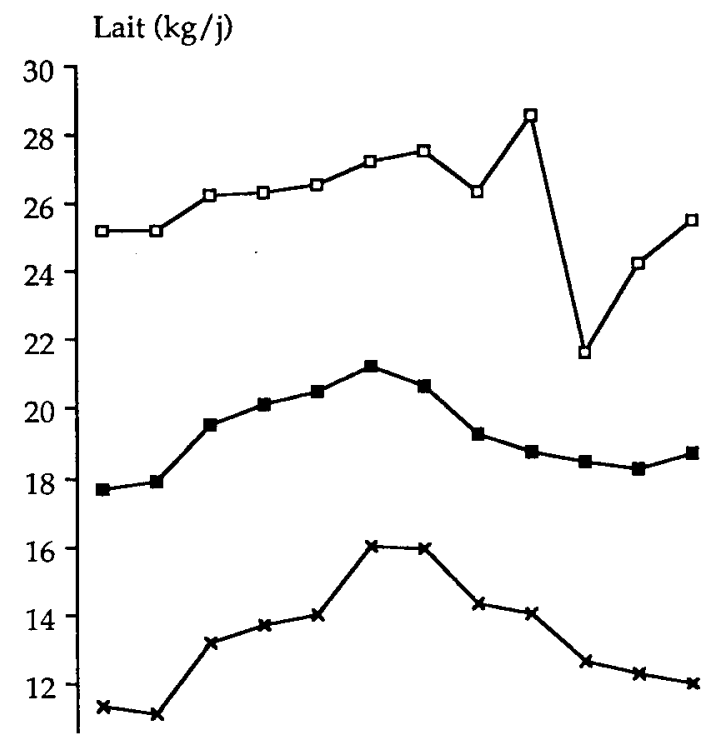

Taux butyreux $(\mathrm{g} / \mathrm{kg})$
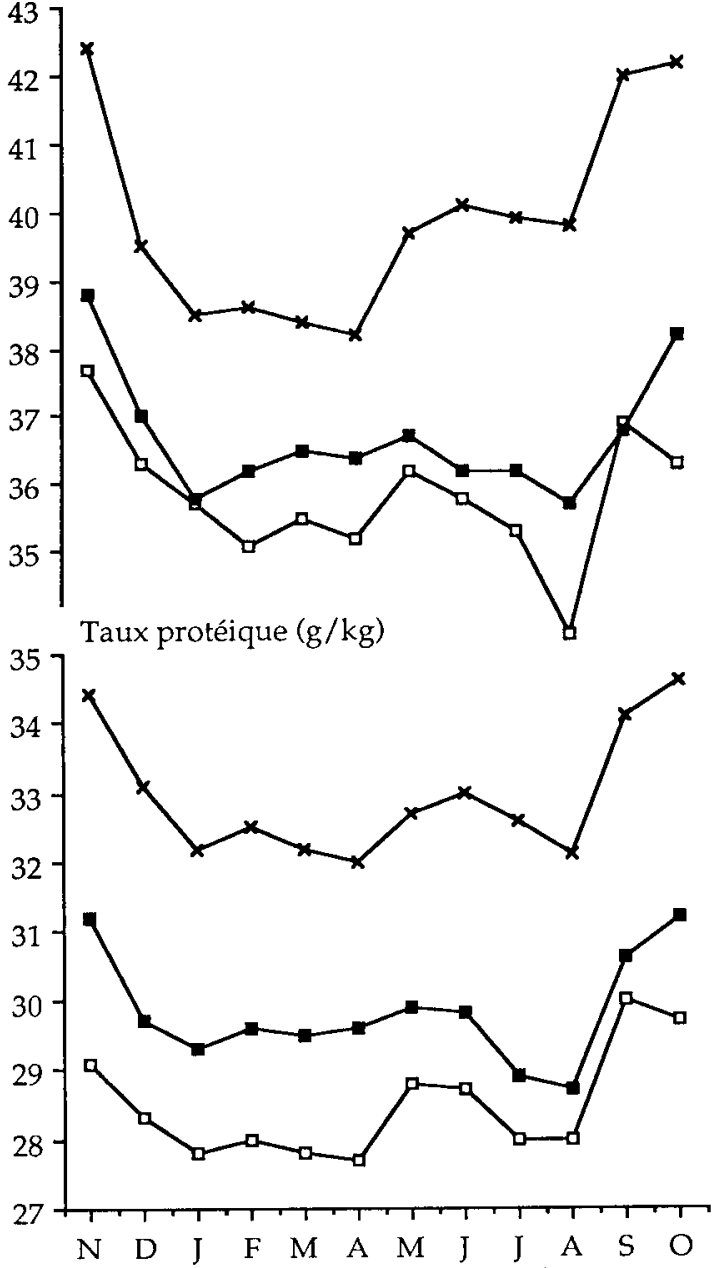

hivernale (Hoden et al 1985). En fait, l'ensemble des facteurs alimentaires ne semble totalement maîtrisé que dans le groupe 4 où l'évolution du taux protéique au cours de l'année est la plus régulière. En particulier, c'est dans ce groupe que la qualité des ensilages est la meilleure. La taille réduite des troupeaux favorise peut-être aussi cette maîtrise, bien qu'à l'échelle du département les résultats de Gestion Technique du Troupeau Laitier semblent montrer le contraire. D'autre part, la prise en compte du seul facteur "période de vêlage » ne permet pas de discriminer efficacement les exploitations sur leur taux protéique (figure 9) : celui ci n'est supérieur que de $0,2 \mathrm{~g} / \mathrm{kg}$ dans les exploitations pratiquant des vêlages d'automne comparativement à celles présentant des vêlages répartis sur toute l'année. Ces résultats s'opposent à ceux obtenus dans d'autres régions (EDE Haute-Saône 1985), vraisemblablement parce que la période de vêlage en ellemême n'est pas un facteur direct de variation du taux protéique annuel, mais un indicateur de la conduite de l'élevage qui, selon les cas, regroupe des facteurs différents et n'a donc pas la même signification. C'est par contre un facteur direct de variation du taux protéique sur de courtes périodes, en particulier en été. En effet, à cette période, à l'effet propre défavorable d'un stade physiologique peu avancé lorsqu'une part importante des vêlages a lieu au printemps, s'ajoute un effet alimentaire lié à la difficulté souvent rencontrée à couvrir les besoins énergétiques élevés des animaux à cette période critique (sécheresse estivale). De même, la seule prise en compte du type de ration de base hivernale utilisée ne permet de mettre en évidence qu'un écart de $0,5 \mathrm{~g} / \mathrm{kg}$ de taux protéique à l'échelle de l'année, sans que l'on puisse d'ailleurs attribuer cette différence à ce seul facteur, compte-tenu des écarts génétiques et de répartition des vêlages entre les exploitations utilisant les 2 types de ration (tableau 1). D'ailleurs, les groupes 3 et 4 ne se différencient pas par le type de ration de base utilisé (respectivement 4 et 5 exploitations sur 7 ayant une ration de type « améliorée »).

Par l'analyse des données individuelles, cette étude a d'autre part permis de mettre en évidence l'effet de la saison sur la production et la composition du lait: les périodes extrêmes et les écarts de production $(3,2 \mathrm{~kg} / \mathrm{j})$ et de composition du lait entre ces périodes (respectivement 3,2 et $2,1 \mathrm{~g} / \mathrm{kg}$ pour le taux butyreux et le taux protéique) sont comparables à ceux obtenus de manière voisine (par élimination de l'effet du stade de lactation) dans des conditions de milieu pourtant très différentes par Waite et al (1956), Spike et Freeman (1967), Lampo et al (1966) et Coulon et al (1988). Ces effets sont en fait la résultante de 2 phénomènes :

1) un effet direct de la saison dont on sait qu'elle agit essentiellement par l'intermédiaire de la durée du jour. La plupart des travaux ont en effet montré qu'une photopériode expérimentale longue ( 15 à $16 \mathrm{~h}$ par jour) augmentait la production laitière et diminuait parfois la richesse du lait en matière utile (Peters et al 1981, Tucker 1985, Bocquier 1985, Stanisiewski et al 1985, Phillips et Schofield 1989). Ces accroissements de production laitière sont associés à une augmentation des quantités ingérées (Peters et al 1981, Phillips et Schofield 1989), alors que la modification des équilibres hormonaux (augmentation de la prolactinémie) (Tucker 1985) pourrait entraîner une dilution des matières secrétées et donc une diminution des taux butyreux et protéique (Bocquier 1985). D'autre part, l'augmentation de la température ambiante (lorsqu'elle se maintient dans la zone 
Tableau 5. Effet du type de ration de base et du groupe d'exploitations sur la production laitière et le taux protéique (données individuelles).

\begin{tabular}{|lcc|}
\hline & $\begin{array}{c}\text { Lait } \\
\text { (kg) }\end{array}$ & $\begin{array}{c}\text { Taux } \\
\text { protéique } \\
\text { (g/kg) }\end{array}$ \\
\hline $\begin{array}{l}\text { Type de ration de base } \\
\text { - améliorée }\end{array}$ & 5704 & 29,6 \\
- classique & $5116^{* *}$ & 29,3 \\
Groupe d'exploitations & & \\
- milieu favorable au TP & 5866 & 30,1 \\
- milieu défavorable au TP & 5319 & $29,1^{* *}$ \\
\hline$* \star * P<0,01$
\end{tabular}

$\star \star: P<0,01$

Valeurs ajustées pour tenir compte de la période de vêlage, du numéro de lactation et de l'index génétique.

de confort thermique des vaches) pourrait avoir un effet propre favorable à la production laitière et défavorable à la richesse du lait, qui s'ajouterait à l'effet de la photopériode (Bocquier 1985, D'Hour et Coulon, non publié).

2) Un effet indirect à plus court terme lié à l'alimentation et à ses modifications. L'écart de production laitière et de taux protéique entre les animaux recevant une ration "améliorée " ou «classique» augmente ainsi au cours de l'hiver, mettant en évidence l'effet cumulatif détériorateur des rations «classiques ». D'autre part, chez les animaux à forts besoins (début de lactation) l'alimentation semble bien être le facteur limitant principal (faible variation de la production au cours de l'hiver, et brutale diminution en août, témoignant de la faiblesse des apports alimentaires à cette période), alors que chez les animaux à faibles besoins (fin de lactation) l'effet de l'alimentation est réduit; l'effet propre de la saison s'exprime alors plus fortement.

Cependant, malgré l'effet défavorable de la saison sur les taux de matière utile en fin d'hiver et au printemps, cette période reste cependant celle où la production de matière utile est la plus élevée, supérieure d'environ $10 \%$ aux quantités produites à l'automne (figure $5 \mathrm{~b}$ ).

En pratique, les effets conjoints de la saison et du stade physiologique des animaux conduisent à des évolutions de la production et de la composition du lait très différentes selon la période de vêlage: comme cela est couramment observé en France et à l'étranger (Blanchard et al 1966, Lampo et al 1966, Miller et al 1969, Coulon et al 1988), les vêlages d'automne ou d'hiver conduisent aux productions laitières et aux taux de matière utile les plus élevés. L'avancement des vêlages en fin d'été-début d'automne peut donc permettre une amélioration des performances des animaux, sous réserve que les démarrages de ces lactations soient bien conduits, ce qui n'a pas été le cas dans cette étude, au moins chez les vaches multipares vêlant en août.

En définitive, cette étude a permis de mettre en évidence l'importance des possibilités d'amélioration des performances des vaches laitières, et en particulier de leur taux protéique, par l'intermédiaire des facteurs de conduite des animaux (alimentation, période de vêlage, ...). Elle montre à la fois l'intérêt d'une analyse globale des facteurs de variations du taux protéique, et les limites d'une approche

Figure 8. Evolution de la production et de la composition du lait selon la période de vêlage, chez les vaches multipares.

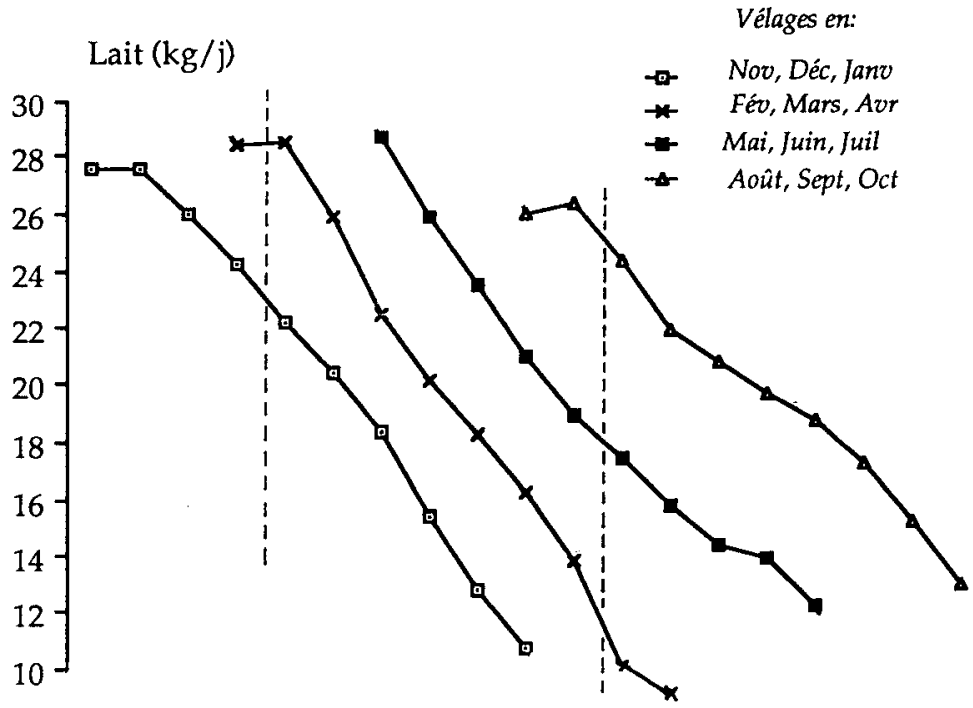

Taux butyreux (g/ $\mathrm{kg})$

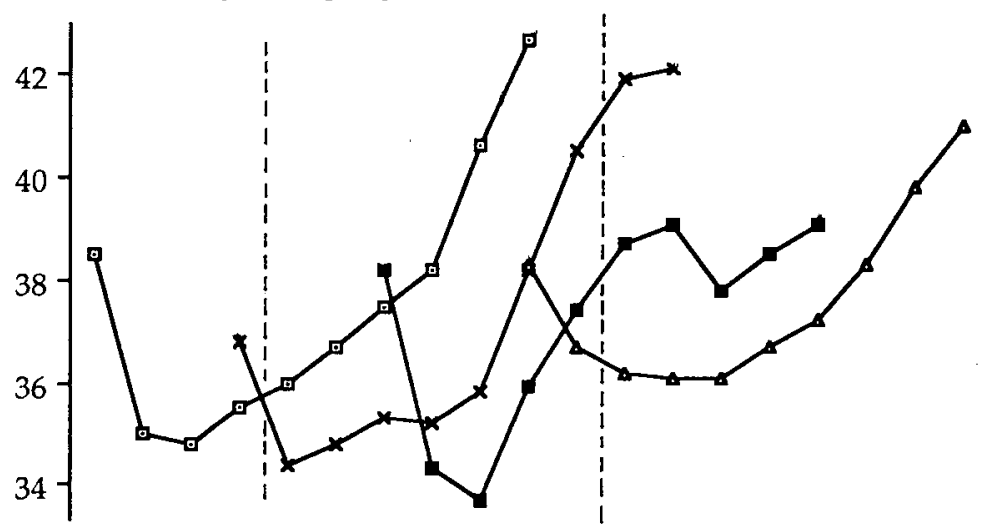

Taux protéique $(\mathrm{g} / \mathrm{kg})$

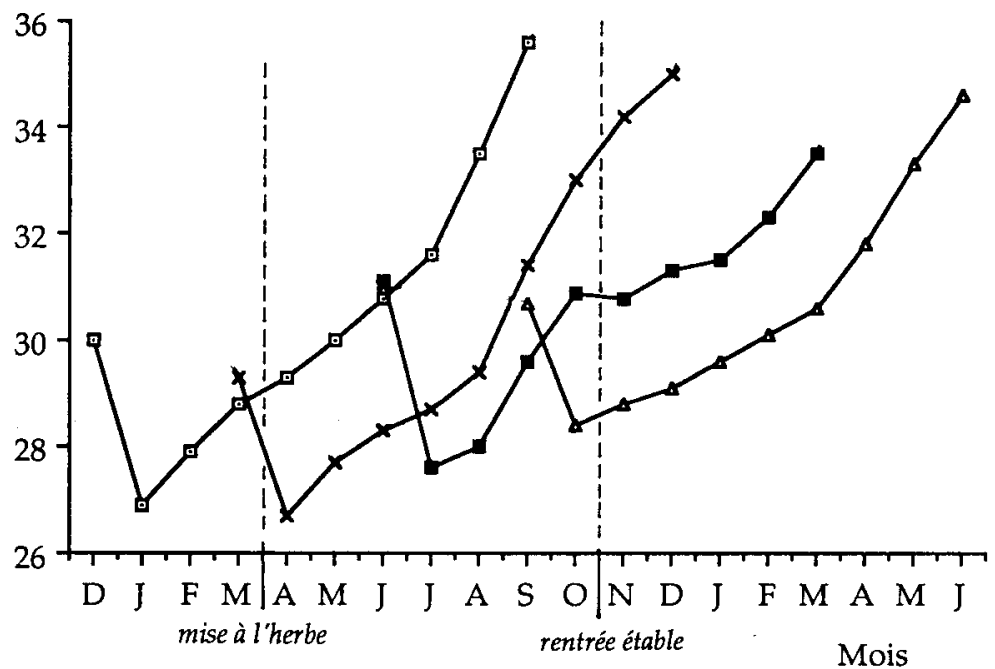


principalement qualitative de ces facteurs. Compte-tenu de la population choisie, il semble indispensable de disposer d'éléments quantitatifs concernant en particulier les apports alimentaires pour mieux préciser les causes de variations des caractéristiques du lait.

Elle a d'autre part montré que la principale période critique de l'année était le mois d'août, ce qui, comme pour l'effet de la période de vêlage, ne pouvait pas ressortir de l'examen des données moyennes obtenues à l'échelle du troupeau. Elle devrait permettre, avec d'autres études du même type conduites dans d'autres conditions de milieu, de mettre au point un outil pratique d'interprétation de ces évolutions à l'échelle du troupeau. Cette utilisation sera développée dans un article ultérieur.

Figure 9. Evolution des caractéristiques du lait selon la répartition des vêlages.

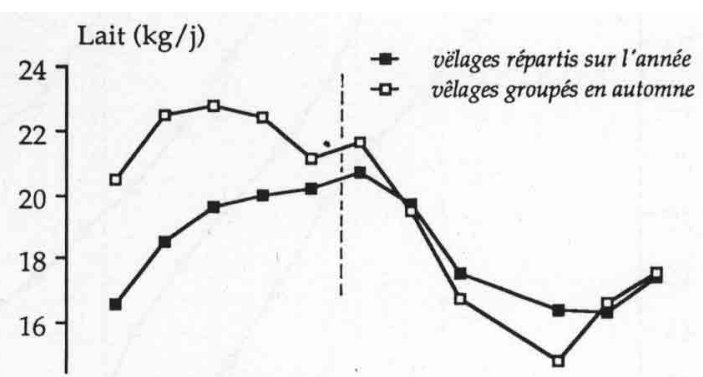

Taux butyreux $(\mathrm{g} / \mathrm{kg})$
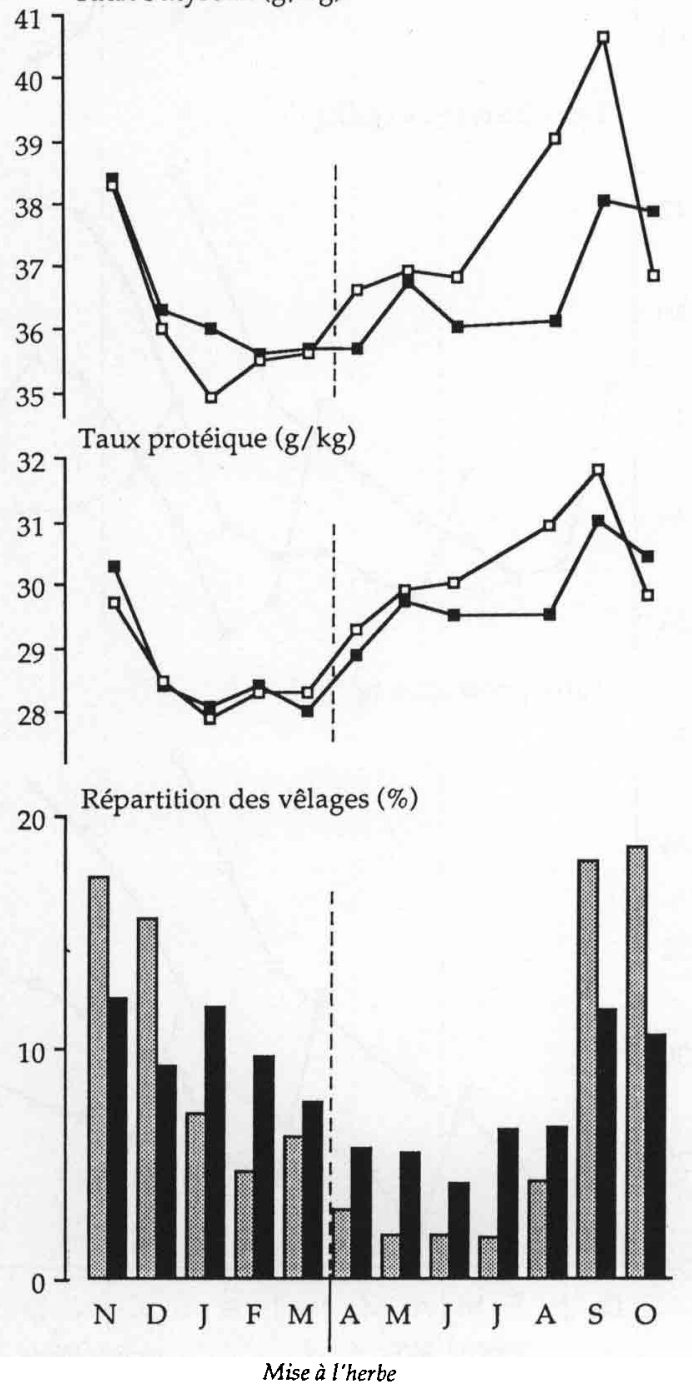

\section{Remerciements}

Nous tenons à remercier les élèves de l'ENITA de Clermont-Ferrand (P. Bouilly, C. Boyer, L. Brunet, D. Delzescaux, G. Dessimond, C. Leroux, C. Leutard, C. Mauchamp, D. Pichon, F. Ranoux, C. Roulin, I. Selin] pour la réalisation des enquêtes chez les éleveurs et leur participation au dépouillement des données. ainsi que P.L. Gastinel pour ses conseils.

\section{Références bibliographiques}

BLANCHARD R.P., FREEMAN A.E., SPIKE P.W., 1966. Variation in lactation yield of milk constituents. J. Dairy Sci., 49, 953-956.

BOCQUIER F., 1985.Influence de la photopériode et de la température ambiante sur certains équilibres hormonaux et sur les performances zootechniques de la brebis en gestation et en lactation. Thèse docteur-ingénieur, INA Paris-Grignon, $105 \mathrm{p}$.

BONAITI B., 1985. Composition du lait et sélection laitière chez les bovins. Bull. Tech. CRZV Theix, INRA, 59 51-61

Contrôle Laitier, 1987 et 1988. Résultats. ITEB et FNOCL, 149 rue de Bercy, 75595 Paris

COULON J.B., BINET M., 1987. Facteurs de variations du taux protéique du lait de vache en exploitation. Etude dans l'aire de ramassage de la coopérative fromagère de Laguiole (Aveyron). Bull. Tech. CRZV Theix, INRA, 68, $11-18$.

COULON J.B., LILAS J.P., 1988. Composition chimique et contamination butyrique du lait: facteurs de variations dans le département de la Haute-Loire. INRA Prod. Anim., 1, 201-207.

COULON J.B., ROYBIN D., CONGY E., GARRET A., 1988. Composition chimique et temps de coagulation du lait de vache: facteurs de variations dans les exploitations du pays de Thônes (Haute-Savoie). INRA Prod. Anim., 1, 253-263.

EDE Haute-Saône et ITG, 1985. Incidence de la conduite alimentaire et des périodes de vêlage des vaches laitières sur les chutes saisonnières du taux protéique du lait.

FAVERDIN P., HODEN A., COULON J.B., 1987. Recommandations alimentaires pour les vaches laitières. Bull. Tech. CRZV Theix, INRA, 70, 133-152.

FROC I., GILIBERT J., DALIPHAR T., DURAND P., 1988. Composition et qualité technologique des laits de vaches Normandes et Pie-noires. 1) Effet de la race. INRA Prod. Anim., 1, 171-178.

HODEN A., COULON J.B., DULPHY J.P., 1985. Influence de l'alimentation sur la qualité du lait. 3. Effets de régimes alimentaires sur les taux butyreux et protéique. Bull. Tech. CRZV Theix, INRA, 62, 69-79.

IARRIGE R., JOURNET M., 1959. Influence des facteurs alimentaires et climatiques sur la teneur en matières grasses du lait. Ann. Nut. Alim., 13, 233-277.

LAMPO Ph. WILLEMS A, VANSCHOUBROEK F 1966. Effect of season, calving period, and stage of lactation on milk yield and milk composition in the cow. Neth. Milk Dairy J., 20, 17-35.

LE DORE A., REMOND B., GRAPPIN R., JEUNET R. JOURNET M., 1986. Teneurs du lait de vache en ses principales fractions azotées et en matières grasses : effet de queloues caractéristiques des animaux et de leur alimentation. Bull. Tech. CRZV Theix, INRA, 63, 13-20.

MILLER P.D., LENTZ W.E., HENDERSON C.R, 1970 Joint influence of month and age of calving on milk yield of holstein cows in the northeastern united states. J. Dairy Sci., 53, 351-357.

PETERS R.R., CHAPIN L.T., EMERY R.S., TUCKER H.A., 1981. Milk yield, feed intake, prolactin, growth hormone and glucocorticoid response of cows to supplemented light. J. Dairy Sci., 64, 1671-1678.

PHILLIPS C.J.C., SCHOFIELD S.A., 1989. The effect of supplementary light on the production and behaviour of dairy cows. Anim. Prod., 48, 293-303.

REMOND B., 1985. Influence de l'alimentation sur la composition du lait de vache. 2 . Taux protéique : facteurs généraux. Bull. Tech. CRZV Theix, INRA, 62, 53-67. 
SPIKE P.W., FREEMAN A.E., 1967. Environmental influences on monthly variation in milk constituents. J. Dairy Sci., 50, 1897-1904.

SUTTON J.D., 1989. Altering milk composition by feeding. J. Dairy Sci., 72, 2801-2814.

STANISIEWSKI E.P., MELLENBERGER R.W., ANDERSON C.R. TUCKER H.A., 1985. Effect of photoperiod on milk yield and milk fat in commercial dairy herds. J. Dairy Sci., 68, 1134-1140.

TUCKER H.A., 1985. Photoperiodic influences on milk production in dairy cows. in " Recent advances in animal nutrition - 1985 ». W. Haresign, D.J.A Cole ed., Butterworths, 211-221.

WAITE R., WHITE J.C.D., ROBERTSON A., 1956. Variations in the chemical composition of milk with particular reference to the solids non fat. 1 . The effect of stage of lactation, season of year and age of cow. J. Dairy Res., 23 $65-81$

\section{Summary}

A survey on protein content in milk from the dairy cow.

A detailed survey was conducted on 42 dairy farms located in Puy-de-Dôme to determine some of the factors in herd management that influence milk protein content. Farm struc- tures, herd structures and feeding practices (during winter and summer) were related to milk protein content. Though these farms had similar breed (friesian) and used similar roughage (grass silage), large variations were noted among farms $(3.2 \mathrm{~g} / \mathrm{kg}$ between annual mean protein content). High protein content was associated with good feeding practices (roughage quality, pasture management), high genetic levels, and calving dates grouped in early winter. The analysis of individual results measured monthly in a total of 1600 cows showed the specific effects of the stage of lactation and of the season on milk production and composition. At the same lactation stage, the months from february to july months showed the lowest protein content but the highest milk production. The differences between extreme months were higher in cows in late lactation than in cows in early lactation. August seemed to be very unfavourable for milk production of cows in early lactation.

AGABRIEL C., COULON J.B., MARTY G., CHENEAU N., 1990. Facteurs de variation du taux protéique du lait de vache: Etude dans des exploitations du Puyde-Dôme. INRA, Prod. Anim., 3 (2), 137-150.

\begin{tabular}{|c|c|c|}
\hline Critères & Classes & Effectif \\
\hline Altitude moyenne de l'exploitation & $\begin{array}{l}100-820 \mathrm{~m} \\
820-1100 \mathrm{~m}\end{array}$ & $\begin{array}{l}21 \\
21\end{array}$ \\
\hline $\begin{array}{l}\text { Pluviométrie moyenne } \\
\text { (station météo la plus proche) }\end{array}$ & $\begin{array}{l}570-1000 \mathrm{~mm} \\
1000-1198 \mathrm{~mm} \\
1198-1680 \mathrm{~mm}\end{array}$ & $\begin{array}{l}13 \\
18 \\
11\end{array}$ \\
\hline SAU de l'exploitation & $\begin{array}{l}29-48 \text { ha } \\
48-210 \text { ha }\end{array}$ & $\begin{array}{l}21 \\
21\end{array}$ \\
\hline Qualité des sols & $\begin{array}{l}\text { Sols profonds } \\
\text { Superficiels ou hydromorphes }\end{array}$ & $\begin{array}{l}17 \\
25\end{array}$ \\
\hline Type de bâtiment & $\begin{array}{l}\text { Stabulation entravée } \\
\text { Stabulation libre ou à logettes }\end{array}$ & $\begin{array}{l}21 \\
21\end{array}$ \\
\hline Principales contraintes de l'exploitation & $\begin{array}{l}\text { - Relief, altitude, présence rochers } \\
\text { - Humidité sols ou sécheresse estivale } \\
\text { - Eparpillement ou éloignement des parcelles }\end{array}$ & $\begin{array}{r}18 \\
15 \\
9\end{array}$ \\
\hline $\begin{array}{l}\text { CARACTERISTIQUES DU TROUPEAU } \\
\text { Effectif vaches }\end{array}$ & $\begin{array}{l}20-32 \\
32-41,2 \\
41,2-67,8\end{array}$ & $\begin{array}{l}14 \\
14 \\
14\end{array}$ \\
\hline Production laitière par vache et par an (kg) & $\begin{array}{l}4213-5373 \\
5373-6021 \\
6021-8955\end{array}$ & $\begin{array}{l}14 \\
14 \\
14\end{array}$ \\
\hline Période principale de vêlage & $\begin{array}{l}\text { - Vêlage automne } \\
\text { (+ } 60 \% \text { sur sept-oct-nov-déc) } \\
\text { - Autres périodes }\end{array}$ & $\begin{array}{l}19 \\
23\end{array}$ \\
\hline \% jours improductifs (G.T.T.L.) & $\begin{array}{l}12-17 \\
17-28\end{array}$ & $\begin{array}{l}19 \\
23\end{array}$ \\
\hline ALIMENTATION DES VACHES LAITIĖRES & & \\
\hline $\begin{array}{l}\text { Prairies temporaires dans la surface fourragère } \\
\text { utilisée par les vaches laitières au printemps } 88\end{array}$ & $\begin{array}{l}\text { Absence } \\
\text { Présence }\end{array}$ & $\begin{array}{l}22 \\
20\end{array}$ \\
\hline $\begin{array}{l}\text { Durée moyenne de séjour des vaches } \\
\text { pour chaque parcelle au printemps (j) }\end{array}$ & $\begin{array}{l}2-4,5 \\
4,5-6,5 \\
6,5-40\end{array}$ & $\begin{array}{l}14 \\
14 \\
14\end{array}$ \\
\hline Déprimage & $\begin{array}{l}\text { oui } \\
\text { non }\end{array}$ & $\begin{array}{l}18 \\
24\end{array}$ \\
\hline Nombre de parcelles utilisées pour pâturage & $\begin{array}{l}1-3 \\
3-5 \\
5-18\end{array}$ & $\begin{array}{l}12 \\
11 \\
19\end{array}$ \\
\hline
\end{tabular}

Annexe 1. Critères retenus dans l'AFC. 


\begin{tabular}{|c|c|c|}
\hline Critères & Classes & Effectif \\
\hline Appréciation de la conduite pâturage (EDE) & $\begin{array}{l}\text { Bon } \\
\text { Moyen } \\
\text { Mauvais }\end{array}$ & $\begin{array}{r}12 \\
23 \\
7\end{array}$ \\
\hline Eloignement des parcelles pâturées (EDE) & $\begin{array}{l}\text { Faible } \\
\text { Moyen ou important }\end{array}$ & $\begin{array}{l}26 \\
16\end{array}$ \\
\hline Abreuvement au pâturage & $\begin{array}{l}\text { Point d'eau } \\
\text { Tonne }\end{array}$ & $\begin{array}{l}23 \\
19\end{array}$ \\
\hline Fumure azotée sur les parcelles ensilées (U/ha) & $\begin{array}{l}0-70 \\
71-117 \\
118-183\end{array}$ & $\begin{array}{l}13 \\
14 \\
15\end{array}$ \\
\hline $\begin{array}{l}\text { Fumure azotée sur les parcelles } \\
\text { pâturées ou fanées au printemps (U/ha) }\end{array}$ & $\begin{array}{l}0-40 \\
41-66 \\
67-200\end{array}$ & $\begin{array}{l}14 \\
14 \\
14\end{array}$ \\
\hline Type de ration hivernale & $\begin{array}{l}\text { améliorée } \\
\text { classique }\end{array}$ & $\begin{array}{l}24 \\
18\end{array}$ \\
\hline Mode de distribution & $\begin{array}{l}\text { à volonté et distribué } \\
\text { à volonté et en libre service } \\
\text { limité et distribué }\end{array}$ & $\begin{array}{l}11 \\
21 \\
10\end{array}$ \\
\hline Qualité du fourrage sec (récolté en 88) & $\begin{array}{l}\text { beaucoup de regain } \\
\text { et/ou foin de bonne qualité } \\
\text { peu de regain et/ou foin médiocre }\end{array}$ & $\begin{array}{l}30 \\
12\end{array}$ \\
\hline Qualité de l'ensilage (récolté en 88) & $\begin{array}{l}\text { conditions de récolte précoces et bonnes } \\
\text { conditions de récolte tardives et/ou mauvaises }\end{array}$ & $\begin{array}{l}35 \\
7\end{array}$ \\
\hline $\begin{array}{l}\text { Notation de l'état de confection } \\
\text { et d'utilisation des silos (silo 87) }\end{array}$ & $\begin{array}{l}\text { bon } \\
\text { moyen, mauvais }\end{array}$ & $\begin{array}{l}22 \\
20\end{array}$ \\
\hline Mode de récolte (ensilage 87) & $\begin{array}{l}\text { coupe directe } \\
\text { ressuyage }\end{array}$ & $\begin{array}{l}32 \\
10\end{array}$ \\
\hline Utilisation·de conservateur (ensilage 87) & $\begin{array}{l}\text { non } \\
\text { acide formique ( } 3 \mathrm{l} / \text { tonne) } \\
\text { autres }\end{array}$ & $\begin{array}{r}22 \\
9 \\
11\end{array}$ \\
\hline Type de silo (ensilage 87) & $\begin{array}{l}\text { silo taupinière } \\
\text { couloir seul ou avec taupinière supplémentaire }\end{array}$ & $\begin{array}{c}6 \\
36\end{array}$ \\
\hline Nombre de silos & $\begin{array}{l}\text { un seul } \\
\text { plusieurs }\end{array}$ & $\begin{array}{l}21 \\
21\end{array}$ \\
\hline $\begin{array}{l}\text { Complément de fourrage pendant la période } \\
\text { de pâturage }\end{array}$ & $\begin{array}{l}\text { pas du tout } \\
\text { transitions } \\
\text { pendant l'été ou l'automne (durée }<2 \text { mois) } \\
\text { pendant l'été ou l'automne (durée }>2 \text { mois) }\end{array}$ & $\begin{array}{r}14 \\
9 \\
11 \\
8\end{array}$ \\
\hline Pratiques alimentaires particulières & $\begin{array}{l}\text { tarissement et/ou début de lactation } \\
\text { aucune }\end{array}$ & $\begin{array}{l}21 \\
21\end{array}$ \\
\hline Note d'état nutritionnel des VL (EDE) & $\begin{array}{l}\text { bon état } \\
\text { moyen ou mauvais }\end{array}$ & $\begin{array}{l}25 \\
17\end{array}$ \\
\hline \multicolumn{3}{|l|}{ GENETIQUE DU TROUPEAU } \\
\hline Index lait (kg) & $\begin{array}{l}-592 \text { à }-185 \\
-184 \text { à }+4 \\
+4 \text { à }+461\end{array}$ & $\begin{array}{l}14 \\
14 \\
14\end{array}$ \\
\hline Index TMMU (g/kg) & $\begin{array}{l}-0,8 \text { à }-0,3 \\
-0,3 \text { à } 0 \\
+0,1 \text { à }+0,7\end{array}$ & $\begin{array}{l}11 \\
17 \\
14\end{array}$ \\
\hline \multicolumn{3}{|l|}{ CARACTERISTIQUES DU LAIT SUR LA CAMPAGNE } \\
\hline Taux butyreux $(\mathrm{g} / \mathrm{kg})$ & $\begin{array}{l}33-35,5 \\
35,6-37,2 \\
37,3-40,7\end{array}$ & $\begin{array}{l}14 \\
14 \\
14\end{array}$ \\
\hline Nombre moyen de cellules $(1000 / \mathrm{ml})$ & $\begin{array}{l}101-229 \\
229-299 \\
299-551\end{array}$ & $\begin{array}{l}14 \\
14 \\
14\end{array}$ \\
\hline Taux protéique moyen $(\mathrm{g} / \mathrm{kg})$ & $\begin{array}{l}27,7-28,8 \\
28,9-29,3 \\
29,4-31,6\end{array}$ & $\begin{array}{l}12 \\
15 \\
15\end{array}$ \\
\hline Taux protéique estival (août) $(\mathrm{g} / \mathrm{kg}$ ) & $\begin{array}{l}27-29,7 \\
29,8-30,7 \\
30,8-33\end{array}$ & $\begin{array}{l}14 \\
14 \\
14\end{array}$ \\
\hline Taux protéique hivernal (mars-avril) (g/kg) & $\begin{array}{l}26-28 \\
28,1-28,9 \\
29-31,5\end{array}$ & $\begin{array}{l}15 \\
10 \\
17\end{array}$ \\
\hline
\end{tabular}

